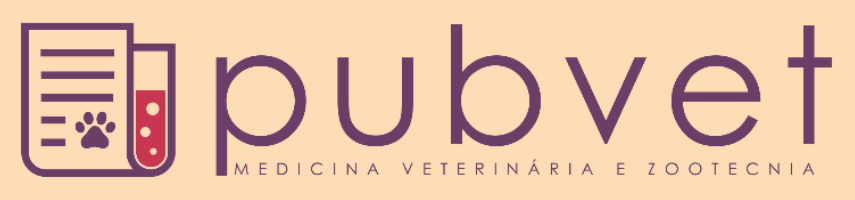

https://doi.org/10.31533/pubvet.v13n5a335.1-7

\title{
Metodologia ativa na educação em medicina veterinária
}

\author{
Gustavo Duarte de Oliveira, $1^{\bullet}$ Vanessa Pavesi de Faria ${ }^{\bullet}$ \\ ${ }^{I}$ Graduando em Medicina Veterinária. Universidade Montes Belos - UniMB. \\ ${ }^{2}$ Professora do curso de Medicina Veterinária. Universidade Montes Belos - UniMB \\ * Autor para correspondência, E-mail: gustavo_duartemusica@hotmail.com
}

\begin{abstract}
Resumo. Este artigo tem o objetivo de investigar o conceito de metodologia ativa e a sua aplicação no curso de medicina veterinária da Universidade Montes Belos (UniMB) - São Luís de Montes Belos, Goiás. A discussão aqui apresentada do tema referido possui como base de composição teórica os estudos de Borges e Alencar (2014) e de alguns teóricos da educação que constituem como integrantes desta metodologia de ensino como Dewey, Vygotsky e Ausubel e Bauman (2007) para contextualização socio-histórica educativa.
\end{abstract}

Palavras-chave: Aluno, aprendizado, independência

\section{Active learning methodologies in education in veterinary medicine}

Abstract. This article aims to investigate the concept of active learning methodologies and its application in the course of veterinary medicine, Montes Belos Universidade (UniMB) - São Luís de Montes Belos, Goiás. The discussion here presented is based on the theoretical composition of the studies by Borges and Alencar (2014) and some education theorists who form part of this teaching methodology, such as Dewey, Vygotsky and Ausubel, and Bauman (2007) for socio-historical educational contextualization

Keywords: Student, learning, independence

\section{Metodología activa en la educación en medicina veterinaria}

Resumen. Este artículo tiene como objetivo investigar o concebir la metodología activa y su aplicación en el curso de medicina veterinaria de la Universidad Montes Belos (UniMB) - São Luís de Montes Belos, Goiás. La discusión que se presenta sobre el tema referido posee como base de composición teórica los estudios de Borges y Alencar (2014) y de algunos teóricos de educación que constituyen como integrantes de la metodología de la enseñanza como Dewey, Vygotsky y Ausubel, e Bauman (2007) para contextualización sociohistórica educativa.

Palabras clave: Estudiante, aprendizaje, independencia

\section{Introdução}

Metodologia Ativa de ensino é um viés de prática educacional emergente no processo de ensino/aprendizagem. Tal ferramenta didática permite que o aluno seja visado como construtor de seu próprio conhecimento e autor de suas conquistas (Borges \& Alencar, 2014; Diesel et al., 2017). Portanto, o acadêmico desenvolve pela sua independência científica, o papel ativo de sua formação. O enfoque da metodologia ativa não está centrado no profissional docente, mas voltada ao papel e posição-sujeito aluno, que revoga o próprio entendimento que se tem da nomenclatura referente ao aprendiz: aluno - o que não tem luz. Luz essa que está implicado a Ciência, a Luz do conhecimento, da visão clara e iluminada da verdade pesquisada cientificamente por experimentos, a verdade comprovada. A 
Metodologia Ativa trabalha com duas frentes de aplicação de ensino. A primeira chamada de PBL Aprendizagem Baseada em Problematização e a segunda, intitulada de Grupo Operativo.

O processo de educar, visto de forma sistêmica, apreende que é preciso ter o professor - papel ativo, livro - mediador e fonte de pesquisa e aluno - papel passivo. Na metodologia ativa, as variantes alteram sem comprometer a equação do processo ensino/aprendizagem, a metodologia ativa impulsiona o acadêmico em formação, a usufruir de todas as oportunidades de aprendizagem através de sua independência de ler, questionar, analisar e, principalmente, agir. Aos olhos da Metodologia Ativa, o processo de ensino/aprendizagem é visto pela equação com as variantes da seguinte forma: aluno - papel ativo, professor - mediador e livro - fonte de pesquisas.

\title{
Metodologia
}

Revisão bibliográfica desenvolvida pelo viés descritivo argumentativo, a nível qualitativo descrições conceituais e exposição teórica para construção do arquétipo argumentativo.

\section{Metodologia ativa: Leitura social e educacional}

Primeiramente, é preciso entender que a sociedade está em constante transformação, reconstruindo e redistribuindo seus valores, aflorando o cultivo e reconhecimento de novos estereótipos sociais e apreendendo com o novo contexto social que a nova geração reside, a medida que, novos percursos são integrados a realidade do sujeito e assim, são traçados novos percursos na história social. Podemos ilustrar esse entendimento com o uso da Internet, a sociedade que usufrui do uso da Internet é diferente da sociedade que não conheceu a realidade virtual. O novo integrante da realidade do sujeito do século XXI reformulou o estilo de vida em sociedade, reconsiderando tweets e posts em redes sociais como marcos ideológicos do pensamento do ser moderno. Essa nova realidade atingiu a esfera educacional, o que pode se tornar um problema se as instituições de ensino não acompanharem as transformações sociais e principalmente, a transformação e evolução do seu público-alvo, os alunos.

Apoiado pela Teoria da Sociedade Líquida, escrita e discutida por Zygmunt Bauman - autor de Modernidade e Ambivalência (1999) e Tempos Líquidos (2007), para confirmar teoricamente o primeiro e segundo parágrafo, o entendimento da constante transformação da sociedade se aplica ao seu estado líquido, a garantia de assumir qualquer formato ao inserido em qualquer tipo de recipiente. A comunidade "pós-moderna", é reconhecida pela teoria como subdesenvolvimento da sua alta capacidade de transformação.

\begin{abstract}
Em primeiro lugar, a passagem da fase "sólida" da modernidade para a "líquida" - ou seja, para uma condição em que as organizações sociais (estruturas que limitam as escolhas individuais, instituições que asseguram a repetição de rotinas, padrões de comportamento aceitável) não podem mais manter sua forma por muito tempo (nem se espera que o façam), pois se decompõem e se dissolvem mais rápido que o tempo que leva para moldá-las e, uma vez reorganizadas, para que se estabeleçam. É pouco provável que essas formas, quer já presentes ou apenas vislumbradas, tenham tempo suficiente para se estabelecer, e elas não podem servir como arcabouços de referência para as ações humanas, assim como para as estratégias existenciais a longo prazo, em razão de sua expectativa de vida curta: com efeito, uma expectativa mais curta que o tempo que leva para desenvolver uma estratégia coesa e consistente, e ainda mais curta que o necessário para a realização de um "projeto de vida" individual. (Bauman, 2007).
\end{abstract}

Consequentemente, a criticidade dessa nova geração também aumentou grandemente. Segundo Diesel et al. (2017), o professor precisa estar preparado e ao mesmo tempo, direcionar seus alunos/orientados a discussões mais profundas a respeito do que está sendo lecionado em sala de aula.

O aumento da criticidade é um fator positivo, é sinal que o aluno está desenvolvimento vários tipos de leitura, como a leitura de mundo. Ler o mundo ao redor e questionar os vários porquês, trazendo o conteúdo ministrado em sala de aula faz com que o acadêmico internalize o conhecimento com maior facilidade. Não haverá somente a voz do professor ecoando as quatro paredes da sala e muito menos, construindo ideologicamente o argumento a ser respondido nas avaliações, ocorrerá, de fato, a construção de um imaginário de ideias e posicionamentos entre o professor e seus alunos. 
De acordo com Santos \& Mortimer (2000), no artigo "Uma análise de pressupostos teóricos da abordagem C-T-S (Ciência - Tecnologia - Sociedade) no contexto da educação brasileira".

\begin{abstract}
[...] permite a introdução de problemas sociais a serem discutidos pelos alunos, propiciando o desenvolvimento da capacidade de tomada de decisão. Para isso, a abordagem dos temas é feita por meio da introdução de problemas, cujas possíveis soluções são propostas em sala de aula após a discussão de diversas alternativas, surgidas a partir do estudo do conteúdo científico, de suas aplicações tecnológicas e consequências sociais.
\end{abstract}

A Educação do hoje não se faz como a de ontem, este paralelo discursivo diz respeito a transformação que a educação vem sofrendo com o manifestar da modernidade. Isto é, se os alunos assumem um novo comportamento em sua formação acadêmica, os professores também precisam acompanhar a atualização do sistema.

De acordo com Borges \& Alencar (2014), a metodologia ativa está construída, no mínimo, por três vieses teóricos de três autores da educação, a aprendizagem pela interação social, Lev Vygotsky (18961934); aprendizagem pela experiência, John Dewey (1859-1952) e aprendizagem significativa, David Ausubel (1918-2008).

\title{
Metodologia ativa: Contribuição de Vygotsky
}

Lev Semenovitch Vygotsky (1896-1934), em sua teoria fez o recorte argumentativo de reconhecer o papel da linguagem no processo de desenvolvimento individual do sujeito e a sua aplicabilidade em concordância com o processo histórico social do mesmo sujeito. Sua problemática está centralizada na capacidade do indivíduo de adquirir conhecimentos pelas suas relações sociais, sua interação com o meio que o cerca. O indivíduo se relaciona pelo seu contexto social e por intermédio do código ao qual está inserido. Nesta perspectiva, é válido ressaltar os tipos de relacionamento que o sujeito integra com o meio como as relações intra e interpessoal. Intrapessoal, é o tipo de relacionamento que o sujeito faz com ele mesmo, nível filosófico; interpessoal, tipo de relacionamento que o sujeito faz com outros indivíduos, família, alunos da mesma sala, com a classe de professores, nível sociológico. Portanto, numa análise escolar ao aplicar a teoria de Vygotsky, o desenvolvimento cognitivo do aluno/acadêmico tem por base no reconhecimento do seu conhecimento prévio (Teoria Aprendizagem Significativa David Ausubel) aliado ao contexto histórico-social que o acompanha em todo o seu período de aprendizagem: pré, durante e pós-sala de aula.

Segundo Coelho \& Pisoni (2012), as autoras do artigo "Vygotsky: sua teoria e a influência na educação"

\footnotetext{
Vygotsky dá um lugar de destaque para as relações de desenvolvimento e aprendizagem dentro de suas obras. Para ele a criança inicia seu aprendizado muito antes de chegar à escola, mas o aprendizado escolar vai introduzir elementos novos no seu desenvolvimento. A aprendizagem é um processo contínuo e a educação é caracterizada por saltos qualitativos de um nível de aprendizagem a outro, daí a importância das relações sociais.
}

Para entender a contribuição da teoria de Vygotsky para Metodologia Ativa, basta ler e inferir os principais objetivos dos escritos do Interacionismo. O desenvolvimento linguístico e a interação do acadêmico em formação em relação a instituição acadêmica: sala de aula, professores, direção e coordenação, mercado de trabalho prepara o agente em formação para o melhor desenvolvimento cognitivo. O interacionismo proposto por Vygotsky coopera com as duas linhas de frente trabalhadas pela Metodologia Ativa: PBL - Aprendizagem Baseada em Problematização (do inglês: PBL - ProblemBased Learning) e Grupos Operativos.

O papel da linguagem em capacitar o acadêmico/pesquisador na habilidade PBL - Aprendizagem Baseada em Problematização para exprimir, expressar, escrever, expor coerentemente e com clareza o seu posicionamento argumentativo seja na fala ou escrita. E no tipo de relacionamento interpessoal, que é reconhecido no campo científico como Interacionismo aplicado a capacitação do Grupo Operativo. É preciso desenvolver a habilidade de construir trabalho em grupo, saber lidar com o pensamento diferente, com propostas metodológicas referentes a pesquisa sendo aplicadas com alguma nova ótica, 
uma nova perspectiva. $\mathrm{O}$ mercado de trabalho seleciona pessoas que sejam bem resolvidas em seus níveis emocional e psicológico para saberem lidar com divergências de opinião, por exemplo.

\title{
Metodologia ativa: Contribuição de Ausubel
}

A essência do processo de aprendizagem significativa é que as ideias expressas simbolicamente são relacionadas às informações previamente adquiridas pelo aluno através de uma relação não arbitrária e substantiva (não literal).

David Ausubel

David Ausubel (1918-2008) foi um psicólogo norte-americano que dedicou sua vida acadêmica para estudar a área da psicologia chamada de Psicologia da Educação. Autor da Teoria da Aprendizagem Significativa escreveu uma série de livros para atestar sua proposta científica como: Psicologia Educacional: uma perspectiva cognitiva (1968), School Learning: An Introduction to Educational Psychology (1969) e The Acquisition and Retention of Knowledge: A Cognitive View (2000).

$\mathrm{O}$ que concerne como primeiro objetivo a desenvolver todo pensamento de Ausubel é o reconhecimento que o aluno não chega à sala de aula vazio, mas com uma medida de conhecimento prévio construído pelo próprio sujeito com sua relação com o mundo - intertexto com Interacionismo de Vygotsky. A Teoria da Aprendizagem significativa expõe a importância do profissional docente em reconhecer o conhecimento prévio de cada aluno em sala de aula, portanto, para a aprendizagem de algum conceito ou conteúdo se tornar significativa para o aluno, será preciso fundamentá-lo em seu conhecimento prévio.

Como expos Ronca (1994) em seu artigo “Teorias de Ensino: Contribuições de David Ausubel”.

\begin{abstract}
Nesta perspectiva, a aprendizagem significativa é um processo cognitivo no qual o conceito de mediação está plenamente presente, pois para que haja aprendizagem significativa é necessário que se estabeleça uma relação entre o conteúdo que vai ser aprendido e aquilo que o aluno já sabe, seja uma imagem. Um conceito ou uma proposição. Se um novo conteúdo interagir com um conceito mais amplo, os efeitos iniciais da inclusividade se darão tanto na facilitação da aprendizagem como na própria retenção.
\end{abstract}

Proposto pelo próprio teórico, a aprendizagem significativa possui uma visão sistêmica alternada em dois pontos, a referência final desta aprendizagem é o resultado do impacto do novo conhecimento na estrutura cognitiva já existente no intelecto do acadêmico em formação. Portanto, os dois fatores que integram o entendimento e assimilação do novo conhecimento se divide em: a) o uso dos novos conceitos e conhecimentos apreendidos e o seu nível de extensão dentro e fora da disciplina e b) o emprego de uma metodologia que facilite a apresentação do novo conhecimento aproveitando a estrutura cognitiva já existente no intelecto do acadêmico em processo de ensino-aprendizagem.

A contribuição de David Ausubel para Metodologia Ativa é a ativação por parte do aluno da importância e significância dos conteúdos ministrados do curso superior para a sua vida tanta acadêmica/pesquisador, quanto futuro integrante do mercado de trabalho. Pelo uso da Metodologia Ativa, o acadêmico precisa instaurar o nível de significado que a aquisição de novos conhecimentos representa para a sua formação profissional. É através da reutilização de seus conhecimentos prévios, de suas leituras prévias e de seus argumentos prévio, que o acadêmico conseguirá internalizar e construir seu próprio conhecimento durante os anos de formação em uma universidade. A graduação precisa fazer sentido e ser levada a sério, por este motivo a teoria de David Ausubel é encarada vulgarmente como a teoria que traz o sentido as coisas.

\section{Metodologia ativa: Contribuição de Dewey}

John Dewey (1859-1952), além de filósofo foi um pedagogista norte-americano. Sendo um dos principais nomes da teoria pedagógica moderna, Dewey é um dos representantes da corrente empregada por Charles Sanders Pierce (1839-1914) e William James (1842-1910), a corrente pragmatista onde se tornou referência no campo de estudos e pesquisa da educação moderna. A contribuição de Dewey para a Metodologia Ativa é a Teoria da Investigação. Para Dewey, a Teoria da Investigação se denota pela 
mudança do ambiente ou por qualquer outra problematização reconhecida pelo sujeito. Tal problemática, faz com que o sujeito que a reconheceu discorra uma série de hipóteses para uma possível solução. Para o autor, esta é uma forma rápida e objetiva para a adaptação do indivíduo ao mundo moderno. A teoria desenvolvida por Dewey pode ser entendida como participante de seu contexto social. O autor passou pela inovação do liberalismo britânico encarado pelos estudos políticos e História Geral como Liberalismo Social, simpatizante ao centro-esquerda política. Ao discorrer possíveis hipóteses a problemática inicialmente reconhecida, o acadêmico estimulará o cognitivo a constante revisão de seus próprios conhecimentos. Na Metodologia Ativa, o aluno aplicará a teoria na frente de trabalho PBL Aprendizagem Baseada em Problematização.

\section{Metodologia ativa: Problematização}

A problematização se dá pelas leituras e discussões orientadas de artigos científicos e publicações bibliográficas que caracterizam a atmosférica científica a ser encarada, sem contar com a participação de professores e profissionais convidados para palestras e rodas de conversa e a formação/organização dos próprios grupos possibilita o amadurecimento do espírito científico individualmente em cada acadêmico integrante.

Estudos de caso são imprescindíveis para o uso da PBL - Aprendizagem Baseadas em Problematização. Um exemplo seria o professor orientador das disciplinas de Parasitologia, Microbiologia ou Patologia expor aos alunos um quadro clínico e exercitar a sala de aula como um todo para gerar uma discussão, para discutir e entender a fisiologia aplicada a análise, os acadêmicos envolvidos precisaram pesquisar as leituras já realizadas e os seus conhecimentos prévios.

É possível encontrar as teorias que constroem a Metodologia Ativa como aprendizagem significativa, pois só está em um grupo operativo quem se dispõe a dedicar tempo e esforço; a aprendizagem pela experiência, pois a troca de opiniões e posicionamentos segundo as interpretações dos alunos e professor corroboram para uma visão mais ampla do assunto discutido e a aprendizagem através da construção individual, que parte da independência e força de vontade ao aprender, ao ler e ao conhecer em particular de cada pesquisador. Graduandos em Medicina Veterinária precisam enxergar a sua atividade enquanto aprendizes de forma ativa e independente.

\section{Metodologia ativa: Grupos operativos}

$\mathrm{Na}$ Medicina Veterinária, a metodologia ativa perscruta a independência de cada acadêmico ao integrá-lo numa realidade de problematização e/ou trabalhos em grupo, ou também chamados de Grupo Operativo. Dentro do curso de Medicina Veterinária da Universidade Montes Belos - UniMM, é perceptível a incitação da aplicação desta metodologia de ensino/aprendizagem através dos grupos de estudos desenvolvidos na universidade, como: GEPA, GEBOV e GEASE.

Grupos Operativos que responsabilizam cada integrante a uma função, como um grupo de operação, umas pequenas comunidades com classe de trabalhadores e hierarquias a serem respeitadas e para que haja um bom funcionamento e oxigenação no sistema como um todo. Os alunos trocam de função para dar oportunidade de crescimento aos novos integrantes.

Os grupos operativos estão sequenciados e divididos por temas, dentro da Medicina Veterinária há segmentos de estudos na saúde animal, como animais domésticos, selvagens e exóticos.

a) GEPA - Grupo de Estudos de Pequenos Animais: estudos de animais domésticos de pequeno, médio e grande porte como cachorros e gatos;

b) GEBOV - Grupo de Estudos em Bovinocultura: estudos de animais domésticos de grande porte de contexto rural;

c) GEASE - Grupo de Estudos de Animais Selvagens e Exóticos: animais que não são domésticos em território nacional (selvagens: macaco, pássaros silvestres, jabotis) e internacional (exóticos: leão, elefantes);

Grupos Operativos integralmente constituídos por alunos e por eles administrados com supervisão de um profissional docente com habilidade na área em específico. Nos Grupos Operativos citados 
anteriormente, possui uma hierarquia para o funcionamento que formam a comissão organizadora: presidente, secretário, mídias, tesoureiro e pesquisador. Em suma, todos alunos envolvidos no grupo de estudos são pesquisadores e, portanto, apresentam seminários, lideram discussões e perfazem as leituras obrigatórias referentes ao estudo sendo analisado.

\section{Metodologia ativa: $\mathbf{O}$ uso de aplicativo de celular e programas de computador}

Houve um tempo nos estudos médicos, sejam humanos ou animais, que para a formação de profissional da saúde seria necessária à utilização de corpos e tecidos vivos. Hoje, a legislação brasileira reconhece como crime a instituição de ensino que utiliza material vivo para ministrar, seja anatomia ou qualquer outra disciplina.

No ano passado, para ser mais preciso no dia 17 de abril de 2018, o Conselho Nacional de Controle de Experimentação Animal (CONCEA) publicou no Diário oficial da União a Resolução Normativa CONCEA n $n^{\circ} 38 / 2018$, que "dispõe sobre restrições ao uso de animais em ensino, em complemento à Diretriz Brasileira para o Cuidado e a Utilização de Animais em Atividades de Ensino ou de Pesquisa Científica-DBCA, conforme o texto da referida resolução". Entretanto, os pesquisadores encontraram novos meios e novas formas de aproximar o conteúdo que antes utilizava tecido vivo para aplicativos de celular e programas de computador.

Hoje, a junta de professores do Curso de Medicina Veterinária da Universidade Montes Belos instiga seus alunos a utilizarem dos seguintes aplicativos e programas para aperfeiçoar seu conhecimento enquanto médicos veterinários em formação:

i) SimNeuro - programa de computador que permite a visibilidade do comportamento a nível celular de retenção e liberação de íons, principalmente da área neurológica;

ii) SimNervo - programa de computador que permite a visibilidade do comportamento a nível celular e posterior a nível tegumentar;

iii) SimMuscle - programa de computador que permite a visibilidade do comportamento a nível celular e posterior a nível tecidual, tecidos musculares e suas variantes: cadiarco, liso e esquelético;

iv) VetSmart CG - aplicativo de celular, bulário digital, auxilia nas disciplinas de farmacologia;

v) Vet Anatomy - aplicativo de celular que permite a visualização da anatomia animal seja a nível sistêmico como: sistema digestivo, cardiovascular, respiratório ou a nível esquelético com imagens 3D;

vi) Touch Surgery - aplicativo de celular que auxilia o residente em cirurgia ou acadêmico de clínica médica a visualizar técnicas cirúrgicas e procedimentos;

vii) Prognosis - aplicativo de celular que permite o acadêmico de patologia, microbiologia ou parasitologia a exercer seus conhecimentos ao resolver casos pelo aplicativo;

\section{Conclusão}

A Metodologia Ativa trabalha com duas frentes operacionais, PBL e Grupos operativos, com a finalidade de capacitar uma geração de pesquisadores moldados em sua independência científica. Acadêmicos que interessam em tomar o papel ativo de sua formação e construir-se como um profissional qualificado e capaz que, a todo momento, busca aperfeiçoar seu conhecimento e habilidades.

\section{Referências bibliográficas}

Ausubel, D. P. (1968). Educational Psychology: A Cognitive View. New York, Holt, Rinehart and Winston.

Ausubel, D. P. (2000). The Acquisition and Retention of Knowledge: A Cognitive View.Springer. 234p.

Ausubel, D. P., Robinson, F. G. \& Hanesian, H. (1969). An Introduction to Educational Psychology.

Holt, Rinehart and Winston, 691p.

Bauman, Z. (2007). Tempos líquidos. Rio de Janeiro, Brasil: Jorge Zahar Ed. 125p 
Bauman, Z. (1999). Modernidade e Ambivalência. Rio de Janeiro, Brasil: Jorge Zahar Ed. 334p

Borges, T. S. \& Alencar, G. (2014). Metodologias ativas na promoção da formação crítica do estudante: o uso das metodologias ativas como recurso didático na formação crítica do estudante do ensino superior. Cairu em Revista, 3(4):119-143.

Coelho, L. \& Pisoni, S. (2012). Vygotsky: sua teoria e a influência na educação. Revista ModelosFACOS/CNE C Osório, 2(2):144-152.

Conselho nacional de controle de experimentação animal - CONCEA, no 38/2018. Disponível em: https://www.jusbrasil.com.br/diarios/186871738/dou-secao-1-19-04-2018-pg-16

Diesel, A., Baldez, A. L. S. \& Martins, S. N. (2017). Os princípios das metodologias ativas de ensino: uma abordagem teórica. Revista Thema, 14(1):268-288.

Ronca, A. C. C. (1994). Teorias de ensino: a contribuição de David Ausubel. Temas em Psicologia, 2(3):91-95.

Santos, W. L. P. \& Mortimer, E. F. (2000). Uma análise de pressupostos teóricos da abordagem CTS (Ciência-Tecnologia-Sociedade) no contexto da educação brasileira. Ensaio Pesquisa em educação em ciências, 2(2).

Recebido: 15 de abril, 2019.

Aprovado: 15 de maio, 2019.

Publicado: 3 de junho, 2019

Licenciamento: Este artigo é publicado na modalidade Acesso Aberto sob a licença Creative Commons Atribuição 4.0 (CC-BY 4.0), a qual permite uso irrestrito, distribuição, reprodução em qualquer meio, desde que o autor e a fonte sejam devidamente creditados. 